\title{
Work in Progress: The Role of Student Counselors at Cybersecurity Summer Camps
}

\section{Mr. Ben Ralph Bernard, North Dakota State University}

Ben Bernard is a Doctoral Candidate in the Department of Computer Science at North Dakota State University and is the Computer Services Specialist for the Department of Architecture \& Landscape Architecture at NDSU with fifteen years of service. Bernard has been professionally recognized for his contributions to NDSU's new cybersecurity educational programs and is the first to be awarded an MS in Computer Science with an Cybersecurity focus at NDSU. His research interests bring new technologies together with creative education and outreach implementations, frequently featuring digital fabrication, augmented \& virtual reality, and cybersecurity education. Bernard leads a team of graduate \& undergraduate design students to research and implement advanced design technologies.

\section{Dr. Jeremy Straub, North Dakota State University}

Jeremy Straub is the Associate Director of the NDSU Institute for Cyber Security Education and Research and an Assistant Professor in the Department of Computer Science at the North Dakota State University. He holds a Ph.D. in Scientific Computing, an M.S. and an M.B.A. and has published over 40 journal articles and over 120 full conference papers, in addition to making numerous other conference presentations. Straub's research spans the gauntlet between technology, commercialization and technology policy. In particular, his research has recently focused on cybersecurity topics including intrusion detection and forensics, robotic command and control, aerospace command and 3D printing quality assurance. Straub is a member of Sigma Xi, the AAAS, the AIAA and several other technical societies, he has also served as a track or session chair for numerous conferences.

\section{Pranay Kumar Marella, Mississippi State University}

Pranay Kumar Marella is an undergraduate researcher at Mississippi State University studying for his Bachelor of Science in Software Engineering. His research interests are in image steganography, Docker, and cybersecurity education. Currently, he is conducting research on Docker registries. 


\title{
Work in Progress: The Role of Student Counselors at Cybersecurity Summer Camps
}

\begin{abstract}
The goal of cybersecurity summer camps is to excite students about cybersecurity and to provide students the opportunity to learn about cybersecurity and related computational science skills. For example, student campers can learn about programming, networks and the Internet. Most importantly, they learn how cybersecurity is deeply interwoven into everyday life. This last summer, 70 high school students participated in the week-long cybersecurity summer camp event at North Dakota State University in Fargo, North Dakota.

The cybersecurity summer camp curriculum is facilitated by junior counselors (students who have completed high school that have a strong interest in cybersecurity), counselors (college students with cybersecurity experience), and university faculty \& staff. This paper studies the impact of having counselors and junior counselors integrated into the cybersecurity summer camp experience and evaluates the impact that being a counselor has on the students that participate in that role. These impacts facilitate cybersecurity community engagement.
\end{abstract}

\section{Introduction}

The need for quality cybersecurity education is growing rapidly due to a significant level of current unfilled demand, which is growing rapidly, for cybersecurity professionals. The proliferation of technology use has caused a corresponding increase in cybercrime, which is estimated to have a global cost of $\$ 6$ trillion annually by 2021 [1]. The demand for cybersecurity professionals has far outstripped the supply and the deficiency impairs society's ability to counter these growing threats. Currently, there are over 300,000 unfilled cybersecurity positions; it has been predicted that there will be 3.5 million cybersecurity job openings by 2021 [2].

The ever-increasing rate of technology implementation in mission-critical roles throughout industry, governments, and society has created a critical shortage of cybersecurity professionals. As cybersecurity is a relatively new career field, many are not aware of the cybersecurity career opportunities and many universities do not have cybersecurity education opportunities. A majority of cybersecurity practitioners were recruited from other fields [3]. In a survey of incoming students, only $1 \%$ were aware of cybersecurity as a career field [4].

To meet the critical national need and demand for cybersecurity, cybersecurity education opportunities need to be widely available across secondary and post-secondary education. $\mathrm{K}-12$ education in the United States is behind in preparing students for computer science or cybersecurity careers. Only 22 states have K-12 computer science standards and only 15 require all high schools to offer computer science curriculum [5]. Just 35\% of high schools teach some form of computer science in the United States [6]. Cybersecurity summer camps may be able to help address these education challenges. 


\section{Background}

This section provides background in two parts; experiential education and project-based learning concepts as integrated into the summer camp format and the creation of the GenCyber summer cybersecurity camp program.

Experiential education in a teaching philosophy in which learners purposefully engage with direct experience to develop skills and increase knowledge while educators facilitate the learning experience [7]. American educational theorist David Kolb describes experiential education as a multidimensional process that begins with concrete experience to reflective observation, then to abstract conceptualization to active experimentation [8]. More simply, the learner experiences, reflects on the experience, learns from the experience, and finally has the opportunity to directly test the new skills and/or knowledge firsthand. The summer camp activity model provides many opportunities for facilitated experiential education activities in an informal and fun environment with a peer group which shares the experience together.

Project-based learning is a model that organizes learning around complex tasks based on challenging problems or questions that directly involve learners in problem-solving, decisionmaking, investigation, and design and culminating in realistic, authentic products and/or presentations [9]. Such projects are central to the learner curriculum, focused on questions or problems that are crafted to drive learners to encounter the central concepts of a discipline, directly involve students in an realistic investigation, and are driven by the learner instead of being led by an instructor [9]. The summer camp format provides many opportunities for learners to collaborate in small groups in project-based learning facilitated by both instructional staff and junior counselors.

The GenCyber program is sponsored by both the National Security Agency and National Science Foundation, providing funding for summer cybersecurity camp experiences for K-12 students and teachers across the United States [10]. The GenCyber program launched in 2014 with eight camps, modeled after the successful strategic language camp program StarTalk [11]. One year later, GenCyber grew to 43 camps in 18 states [11]. In the summer of 2019, GenCyber reached 123 summer camps in 38 states plus the District of Columbia and Puerto Rico [12]. GenCyber camps can be hosted at public or private school systems, colleges, universities, or non-profit institutions and provide options for either K-12 students or K-12 teachers; all camps are free for attendees [10].

The three goals of the GenCyber program are to increase interest in cybersecurity and diversity in the cybersecurity workforce in the United States, help all students understand correct and safe on-line behavior, and improve teaching methods and cybersecurity content for K-12 curricula [13].

Colleges and universities are natural partners for the GenCyber program as many are already active in community engagement and outreach to prepare youth for careers in cybersecurity [10]. In particular, North Dakota State University is a state land-grant institution that relied on key 
relationships with educators in school districts across the state, education technologists in state government, and university students and staff to both recruit for and host the GenCyber program.

Traditional summer camps are frequently staffed by 'counselors' aged 15-17, which provides the camp participants 'near-peer' role models [14]. In many cases, these counselors have recently attended the camp they are counseling at or another similar camp. This contrasts with the typical secondary education environment in which the instructional staff is all older adults. Counselors were recruited from regional undergraduate and graduate students and camp participants who were incoming freshmen at North Dakota State University to provide cybersecurity summer camp participants 'super-peer' role models and cyber leadership experience for the student counselors [15].

Training was provided for the student counselors prior to the 5-day cybersecurity summer camp consisting of camp protocol, procedures, activities, and cyber leadership training.

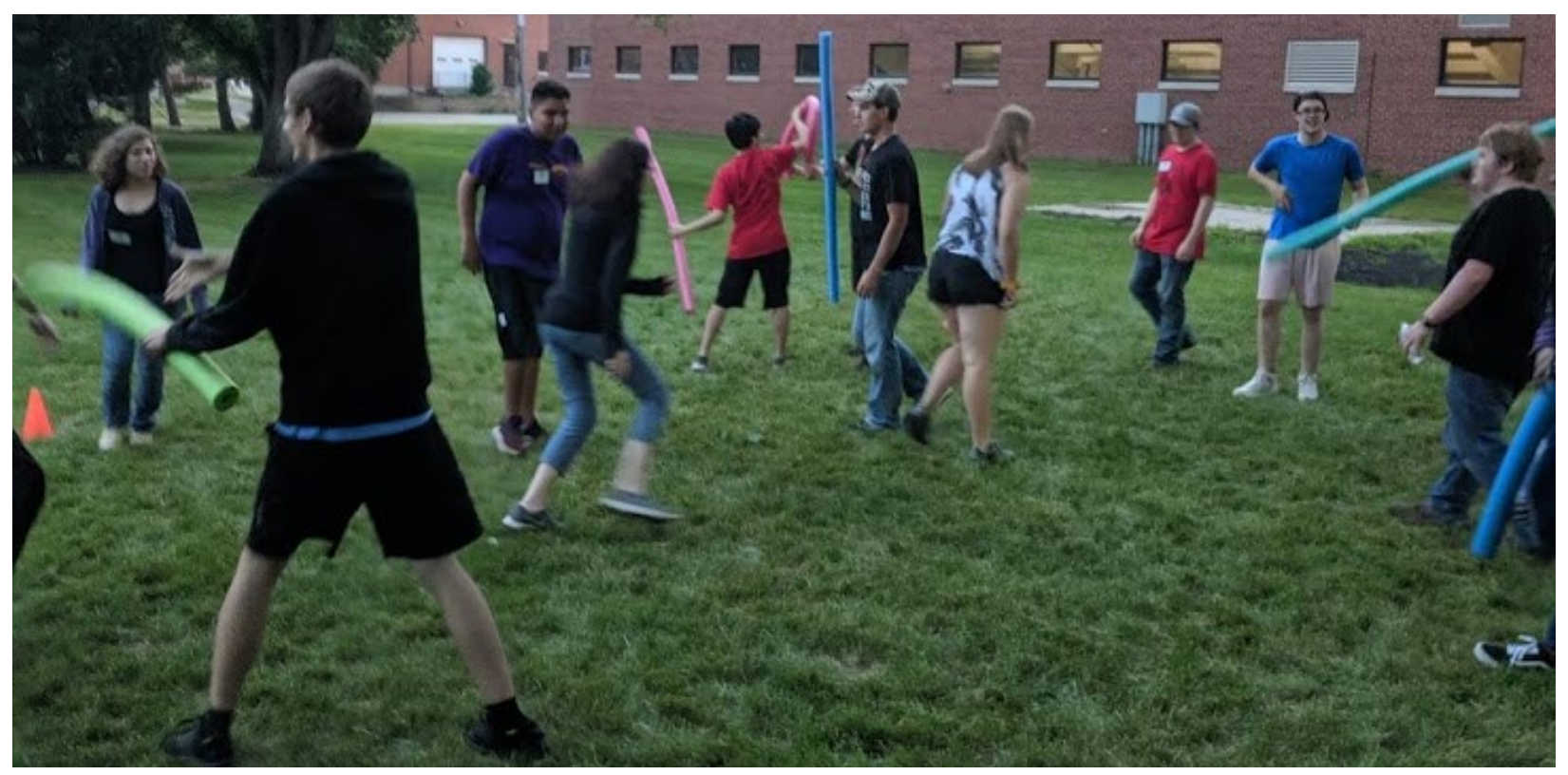

Figure 1. Student Counselors facilitating an evening camp activity.

\section{Student Counselor Impact}

Student counselors enhanced the learning experience of the campers at the cybersecurity summer camp by attending the technical classes with campers, being available to assist students and instructional staff as needed. For example, a camper was having trouble using the Linux terminal, so the junior counselor sat next to the camper and helped her while the class was still going on. This enabled the instructor to continue the workshop without interruption. Student counselors also role modeled class participation by 'breaking the ice' and asking questions to instructional staff to encourage the campers to do the same.

Junior counselors assisted instructional staff with workshop equipment preparation, setup and cleanup as needed, freeing up instructional staff for additional instructional time with student 
campers. This key role also allowed for additional workshops to be made available to students as campus space availability changed several times over the course of the camp, forcing workshop equipment to be moved from building to building with prompt setup required to keep the schedule on time.

Frequently, campers asked student counselors for assistance with the camp curriculum. During one workshop, students were using Kali Linux and Wireshark to view network packets. A junior counselor helped out a student camper who was having difficulty with the Linux terminal. Afterwards, the student asked the counselor questions about packets and network traffic. Without the extra assistance, the student camper would not have mastered the material.

Junior counselors helped ease the stress of being at the camp and keeping the campers on schedule by escorting them from event to event across campus, using the walking time to further get to know the student campers and answer questions on the various cybersecurity challenges and daily schedule.

As campers and student counselors participated in camp 'ice breakers' - activities designed to encourage communication, rapport, and friendships between campers and staff - campers frequently would ask their near-peer student counselors questions about how to succeed in high school, how to find the right college, and how to continue learning more about cybersecurity. One particularly successful event was a panel discussion between campers and student counselors, providing a forum for campers to ask questions about college, cybersecurity classes and careers from the near-peer counselor perspective. Junior counselors provided encouragement and advice to campers on how to be successfully complete high school and how to apply for college scholarships. Junior counselors shared their college cybersecurity research experiences with the student campers. Two student campers asked a counselor how to start a high school robotics club. Mentor relatability is a significant factor in the success of summer camp [16].

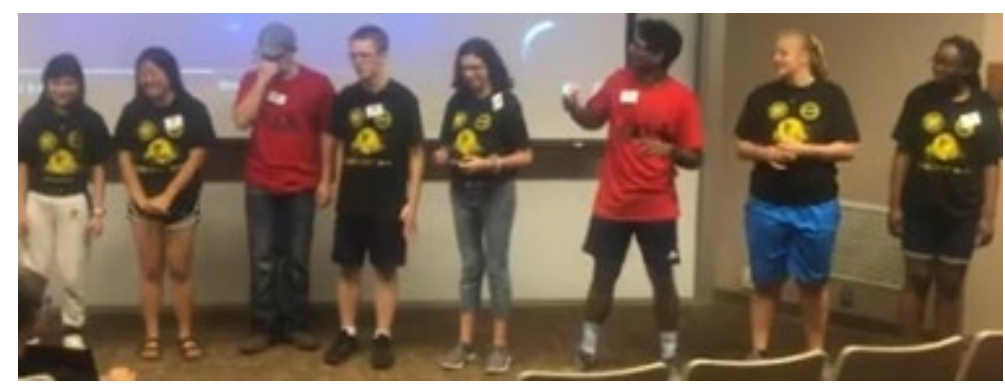

Figure 2. Student Counselors and campers interacting.

Over the course of the camp, student counselors found opportunities to assist instructional staff in improving the curriculum and added valuable content that was not originally planned. For example, instructional staff provided a cybersecurity card game used to teach key cybersecurity concepts but had to leave early. A junior counselor was able to fill in and create a new activity that incorporated the card game in a way that was much more fun for the student campers while teaching the cybersecurity concepts better. 
Junior counselors introduced the campers to cybersecurity 'Capture The Flag' (CTF) competitions and coached a live cybersecurity CTF event with camper teams. This collaboration between the student counselors and cybersecurity campers became a very popular camp activity; the cybersecurity campers asked the student counselors for additional CTF resources and were interested in setting up similar competitions in their high schools. Junior counselors enjoyed the opportunity to gain cybersecurity coaching experience and were able quickly apply lessons learned from the instructional staff to their first instructional experience.

The junior counselors reported many benefits from their participation in the cybersecurity summer camp. Several cited the experience as motivation towards a future cybersecurity career. One student counselor is now pursuing cybersecurity education research as a Ph.D. candidate and another is considering graduate cybersecurity studies after returning this summer for a second summer of counselor experience. Student counselors and campers both reported making lasting friendships as a result of the cybersecurity camping experience.

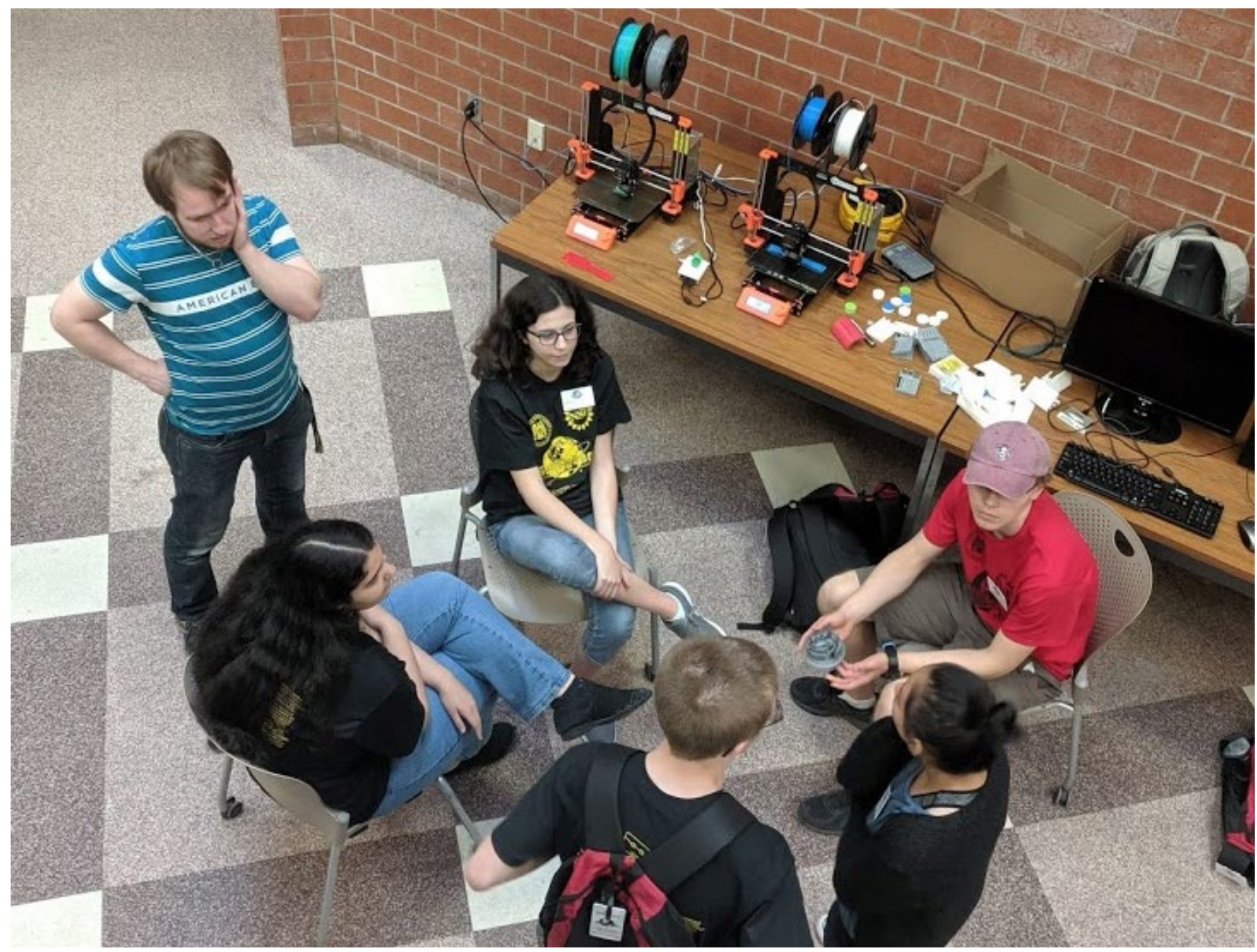

Figure 3. Student Counselors leading a workshop at the cybersecurity summer camp. 


\section{Methodology}

The data used to measure the role of junior counselors will be collected using two separate surveys. The first survey is a survey for the day campers that will include some questions about student counselors and the counselor's effects on the camper's experience. The second survey is for junior counselors and how the counselors felt about their role as a student counselor at the camp. Questions from both surveys can be found in the Appendix. Responses to the survey will be vary from "Strongly Agree, Agree, Not Sure, Disagree, and Strongly Disagree" to "Yes or No" type of questions. The surveys will be created and distributed using Qualtrics.

\section{Conclusion \& Future Work}

This paper starts to answer the role of junior counselors within the cybersecurity summer camp curriculum as a means of enhancing the camper experience, providing a valuable cyber leadership opportunity for the student counselors themselves, and facilitating cybersecurity community engagement.

A survey of both the cybersecurity summer camp participants and junior counselors is awaiting IRB approval to further investigate the impact student counselors have on cybersecurity community engagement. We suspect the survey data will show a strong correlation between cybersecurity summer camp participation satisfaction and junior counselor participation satisfaction, as well as increased interest in the cybersecurity career field.

\section{Acknowledgments}

Funding for the summer 2019 GenCyber camp was provided by the National Security Agency (award \# H98230-19-1-0123). Thanks are given to Pratap Kotala, Simone Ludwig, Dakota State University and others who contributed to offering the 2019 GenCyber camp and NDSU. 


\section{Appendix}

The questions that the students are being asked regarding student counselors are as follows:

\section{Table 1. Survey Questions for Campers}

\begin{tabular}{|l|l|}
\hline Questions & Possible Responses \\
\hline $\begin{array}{l}\text { The junior counselors improved my } \\
\text { experience at the camp. }\end{array}$ & $\begin{array}{l}\text { Strongly Agree, Agree, Not Sure, Disagree, } \\
\text { Strongly Disagree }\end{array}$ \\
\hline Junior counselors communicated effectively. & $\begin{array}{l}\text { Strongly Agree, Agree, Not Sure, Disagree, } \\
\text { Strongly Disagree }\end{array}$ \\
\hline $\begin{array}{l}\text { Junior counselors displayed appropriate } \\
\text { leadership skills. }\end{array}$ & $\begin{array}{l}\text { Strongly Agree, Agree, Not Sure, Disagree, } \\
\text { Strongly Disagree }\end{array}$ \\
\hline $\begin{array}{l}\text { Would you be interested in serving as a } \\
\text { counselor in the future? }\end{array}$ & Yes, No \\
\hline
\end{tabular}

The questions that the student counselors are being asked regarding their experience as a counselor are as follows:

Table 2. Survey Questions for Student Counselors

\begin{tabular}{|l|l|}
\hline Questions & Possible Responses \\
\hline $\begin{array}{l}\text { Being a junior counselor at the cybersecurity } \\
\text { camp has improved my leadership skills. }\end{array}$ & $\begin{array}{l}\text { Strongly Agree, Agree, Not Sure, Disagree, } \\
\text { Strongly Disagree }\end{array}$ \\
\hline $\begin{array}{l}\text { Being a junior counselor has helped me } \\
\text { prepare for college. }\end{array}$ & $\begin{array}{l}\text { Strongly Agree, Agree, Not Sure, Disagree, } \\
\text { Strongly Disagree }\end{array}$ \\
\hline $\begin{array}{l}\text { Junior counselors had a strong role in making } \\
\text { the cybersecurity summer camp successful. }\end{array}$ & $\begin{array}{l}\text { Strongly Agree, Agree, Not Sure, Disagree, } \\
\text { Strongly Disagree }\end{array}$ \\
\hline $\begin{array}{l}\text { I enjoyed being a junior counselor. } \\
\text { Wtrongly Agree, Agree, Not Sure, Disagree, } \\
\text { Strongly Disagree }\end{array}$ \\
\hline $\begin{array}{l}\text { Wybersecurity summer camp counselor in the } \\
\text { future? }\end{array}$ & Yes, No \\
\hline $\begin{array}{l}\text { What would you change about the role of } \\
\text { junior counselors? }\end{array}$ & Free Response \\
\hline
\end{tabular}




\section{References}

[1] “Cybercrime Damages \$6 Trillion by 2021.” [Online]. Available: https://cybersecurityventures.com/hackerpocalypse-cybercrime-report-2016/. [Accessed: 03-Feb-2020].

[2] "Cybersecurity Talent Crunch To Create 3.5 Million Unfilled Jobs Globally By 2021." [Online]. Available: https://cybersecurityventures.com/jobs/. [Accessed: 03-Feb-2020].

[3] "Cybersecurity is heading into a recruitment crisis: Here's how we fix the problem | ZDNet." [Online]. Available: https://www.zdnet.com/article/cybersecurity-is-headinginto-a-recruitment-crisis-heres-how-we-fix-the-problem/. [Accessed: 26-Nov-2019].

[4] "State of Cybersecurity 2019 Part 1: Current Trends in Workforce Development," 2019.

[5] "2018 State of Computer Science Education Policy and Implementation Advocacy Coalition."

[6] "Only 3 Percent Of U.S. Bachelor's Degree Grads Have Cybersecurity Related Skills." [Online]. Available: https://cybersecurityventures.com/only-3-percent-of-u-s-bachelorsdegree-grads-have-cybersecurity-related-skills/. [Accessed: 18-Dec-2019].

[7] "What is EE." [Online]. Available: https://www.aee.org/what-is-ee. [Accessed: 01-May2020].

[8] D. Efstratia, "Experiential Education through Project Based Learning," Procedia - Soc. Behav. Sci., vol. 152, pp. 1256-1260, 2014.

[9] J. W. Thomas, “A REVIEW OF RESEARCH ON PROJECT-BASED LEARNING The Autodesk Foundation 111 McInnis Parkway San Rafael, California 94903 (415) 507-6336 Fax (415) 507-6339 http://www.autodesk.com/foundation," 2000.

[10] "GenCyber - FAQ." [Online]. Available: https://www.gen-cyber.com/faq/. [Accessed: 03Feb-2020].

[11] T. ; Abegaz and K. Antonia, "Planning and Implementing a Successful NSA-NSF GenCyber Summer Cyber Academy," 2016.

[12] "2019 GenCyber Camp Locator.” [Online]. Available: https://www.gencyber.com/camps/. [Accessed: 03-Feb-2020].

[13] “2020 GenCyber Camp Proposals.” [Online]. Available: https://www.gencyber.com/host/. [Accessed: 03-Feb-2020].

[14] M. Riley, J. Sibthorp, and D. Bialeschki, "Counselor- and Leader-in Training Programs at American Camp Association Camps: Results from the 2017 CIT/LIT Program Survey."

[15] J. Straub, G. Ingwalson, and R. Fevig, "A Design for Inspiring Students with Near-Space Exploration," J. Aviat. Educ. Res., 2013.

[16] J. Clarke-Midura, F. Poole, K. Pantic, M. Hamilton, C. Sun, and V. Allan, "How near peer mentoring affects middle school mentees," in SIGCSE 2018 - Proceedings of the 49th ACM Technical Symposium on Computer Science Education, 2018, vol. 2018-January, pp. 664-669. 